\title{
Desenvolvimento e validação de técnica quantitativa de análise de imagem para avaliação do teste do cometa corado pela prata
}

\author{
Development and validation of a quantitative image analysis method to evaluate comet assay (silver staining)
}

Gabrielli Brianezi ${ }^{1}$; João Lauro Viana de Camargo²; Hélio Amante Miot ${ }^{3}$

unitermo
Teste do cometa
Genotoxicidade
Análise de imagem
Método quantitativo

\section{resumo}

Introdução: $O$ ensaio do cometa ou técnica da eletroforese de células isoladas é largamente empregado para avaliação de danos e reparo do DNA em células individuais. O material pode ser corado por técnicas de fluorescência ou por sal de prata. Este último apresenta vantagens técnicas, como o tipo de microscópio utilizado e a possibilidade de armazenamento das lâminas. A análise dos cometas pode ser feita de modo visual, porém há a desvantagem da subjetividade dos resultados, que pode ser minimizada por análise digital automatizada. Objetivos: Desenvolvimento e validação de método de análise digital de cometas corados por sal de prata. Métodos: Cinquenta cometas foram fotografados de maneira padronizada e impressos em papel. Além de medidas manualmente, essas imagens foram classificadas em cinco categorias por três avaliadores, antes e depois de pré-processadas automaticamente pelo software Image) 1.38x. As estimativas geradas pelos avaliadores foram comparadas quanto sua correlação e reprodutibilidade. Em seguida, foram desenvolvidos algoritmos de análise digital das medidas, com base em filtros estatísticos de mediana e de mínimo. Os valores obtidos foram comparados com os estimados manual e visualmente após o pré-processamento. Resultados: As medidas manuais das imagens pré-processadas apresentaram maior correlação intraclasse do que as imagens preliminares. Os parâmetros automatizados apresentaram alta correlação com as medidas manuais pré-processadas, sugerindo que este sistema aumenta a objetividade da análise, podendo ser utilizado na estimativa dos parâmetros dos cometas. Conclusão: A presente análise digital proposta para o teste do cometa corado pela prata mostrou-se factível e de melhor reprodutibilidade que a análise visual.

\section{abstract}

Background: Comet assay or single cell gel electrophoresis is a useful and widely applied technique for the assessment of DNA damage and repair in individual cells. Nuclei can be stained with fluorescence methods or silver salts. The latter has technical advantages such as the type of microscope used and the possibility of slide storage. Comet analysis may be performed visually, however, there is the disadvantage of subjective results, which can be minimized by automated digital analysis. Objectives: Development and validation of digital analysis method for silver stained comet assays. Methods: Fifty comets were photographed in a standardized way and printed on paper. Before and after being automatically preprocessed by Imagel $1.38 \mathrm{x}$ software, the images were manually measured and classified into five categories by three evaluators. Their estimates were compared as to their correlation and reproducibility. Afterwards, an algorithm for automated digital analysis of the comet measurements was developed based on statistical filters of median and minimum. These results were compared with those manually and visually estimated after preprocessing. Results: Manual measurements of preprocessed images showed higher intraclass correlation than the original ones. Automated results had high correlation with the pre-processed manual measurements, suggesting that this system increases objectivity and can be used in the estimation of comet parameters. Conclusions: Digital analysis of silver stained comet assay proved to be feasible and better reproducible than the visual analysis. key words

Comet assay

Genotoxicity

Image analysis

Quantitative method

1. Biomédica do Núcleo de Avaliação do Impacto Ambiental sobre a Saúde Humana (TOXICAM) do Departamento de Patologia da Faculdade de Medicina de Botucatu da Universidade Estadual Paulista (FMB/UNESP).

2. Professor titular do Departamento de Patologia; responsável pelo TOXICAM do Departamento de Patologia da FMB/UNESP.

3. Professor doutor do Departamento de Dermatologia e Radioterapia da FMB/UNESP.

Trabalho realizado no TOXICAM do Departamento de Patologia da FMB/UNESP.

Agência Financiadora: Fundação de Amparo à Pesquisa do Estado de São Paulo (FAPESP, Proc. 07/56371-6).

Trabalho apresentado na 60ª Reunião Anual da Sociedade Brasileira para o Progresso da Ciência (SBPC), realizada de 13 a 18 de julho de 2008, na Universidade Estadual de Campinas (UNICAMP). 


\section{Introdução}

O ensaio do cometa, ou técnica da eletroforese celular em microgel, é muito útil e largamente empregado para avaliação de danos e reparos de DNA em células individuais. Seu princípio básico é o da lise de membranas celulares, seguida pela indução da migração eletroforética do DNA liberado em matriz de agarose. Quando vista ao microscópio, a célula migrada adquire a forma aparente de um cometa, com cabeça, a região nuclear, e cauda, que contém fragmentos ou fitas de DNA que migraram na direção do ânodo. A análise dos cometas baseia-se no grau de fragmentação do DNA e sua migração pela microeletroforese. Medidas como o comprimento total da "cauda" e a densidade de DNA fornecem dados indiretos sobre o estado do DNA da amostra.

Inicialmente, a técnica foi desenvolvida para visualizar danos de DNA induzidos por radiação em células de mamíferos ${ }^{(23)}$. Atualmente, esse método é amplamente usado como ensaio de genotoxicidade de produtos industriais, farmacêuticos e agroquímicos, para detectar danos e reparos do DNA em células individuais. É um método rápido, de baixo custo, seguro e de execução relativamente fácil.

Há duas versões do ensaio de cometa: a neutra ${ }^{(22)}$ é considerada menos sensível porque detecta apenas lesão de fita dupla de DNA; a alcalina, descrita por Singh et al. ${ }^{(25)}$ e utilizada nesse estudo com algumas modificações $(11,13,20)$, é adotada pela maioria dos laboratórios por detectar maior variedade de lesões de DNA, como quebra de fita simples, lesões de sítios alcalinos lábeis e locais de reparos incompletos e crosslinks ${ }^{(10)}$.

Os cometas resultantes da corrida eletroforética do DNA necessitam passar por um processo de coloração, que pode ser feito alternativamente por técnicas de fluorescência, em que são usados brometo de etídio, iodeto de propídio e cyber green, ou por histotécnica convencional com sal de prata. Esses métodos apresentam diferentes vantagens e limitações. As maiores limitações da fluorescência são a necessidade de microscópio próprio para análise de material fluorescente e a impossibilidade de armazenamento das lâminas para observação posterior, porque a coloração desbota-se em um dia. Já sob coloração com sal de prata, a análise pode ser feita com microscópio óptico convencional e as lâminas podem ser armazenadas para análise posterior. Outra desvantagem da coloração fluorescente é a toxicidade de alguns reagentes, como o brometo de etídio, que é mutagênico e, sob exposição crônica, pode ser cancerígeno ${ }^{(20)}$. Quando comparadas, as duas colorações não diferem com relação aos resultados das imagens obtidas, sendo, portanto, equivalentes ${ }^{(12,20)}$.

No teste do cometa podem ser utilizadas células de grande variedade de tecidos, desde que possam ser adequadamente isoladas. $\mathrm{O}$ uso de linfócitos periféricos é muito conveniente porque as células já se encontram em suspensão (sangue) e não necessitam da ação de enzimas ou de processo mecânico para seu isolamento. Esses processos, principalmente o enzimático, podem causar danos adicionais ao DNA. Outras vantagens do uso de linfócitos são a facilidade de sua obtenção em grande número, dispensando a fase de cultura celular, o fato de as células estarem quase todas na mesma fase do ciclo e, finalmente, por refletirem o estado do organismo como um todo(7).

As medidas dos cometas realizadas visualmente são imprecisas devido à subjetividade do observador. Em consequência, têm menor uniformidade e baixa reprodutibilidade em diferentes laboratórios ${ }^{(4)}$. A variabilidade relativamente alta dessas medidas impede a detecção de pequenos efeitos genotóxicos. Para evitar esta limitação, há necessidade de amostras celulares mais numerosas.

O uso de um sistema por análise de imagem pode contribuir para a minimização dos problemas de subjetividade e tornar o teste do cometa mais objetivo e com maior reprodutibilidade. Métodos quantitativos de análise de imagem automatizados permitem obter parâmetros, como comprimento total do cometa e comprimento, densidade (porcentagem de DNA) e momento da cauda ${ }^{(5,15)}$.

\section{Objetivos}

Desenvolver e validar um sistema de análise de imagem digital para avaliação quantitativa de cometas corados por nitrato de prata.

\section{Material e método}

\section{Aquisição do material}

Foram utilizadas células do sangue periférico de ratos Wistar machos com oito semanas de idade, pesando em média 200 g, provenientes do Centro Multidisciplinar para Investigação Biológica da Universidade Estadual de Campinas (CEMIB/UNICAMP). Os animais foram manti- 
dos em gaiolas de polipropileno, com dimensões de 41 $\times 34 \times 16$ centímetros, forradas com maravalha de pinho autoclavada, trocadas três vezes por semana. Durante os experimentos os animais permaneceram no biotério do Departamento de Patologia da Faculdade de Medicina de Botucatu da Universidade Estadual Paulista (FMB/UNESP) recebendo ração basal peletizada (Biobase, Bio-tec, Bases Química Ltda., Colombo-PR) e água filtrada ad libitum, em uma sala com temperatura a $22^{\circ} \mathrm{C}$, umidade relativa de $55 \%$, ciclo de luz de 12 horas claro/escuro e exaustão contínua do ar ambiente. Após período de aclimatação de duas semanas, os ratos foram casualizados e separados em lotes de cinco animais por gaiola.

Para a produção dos cometas, os animais foram tratados com N-nitroso-N-metilurea (MNU) (CAS 68493-5, Sigma Aldrich, Milwalkee), em dose de $50 \mathrm{mg} / \mathrm{kg}$ intraperitoneal (IP), em solução com $\mathrm{NaCl} 0,9 \%$, de forma a permitir a administração de $1 \mathrm{ml} / 100 \mathrm{~g}$ de peso corpóreo. Amostras de sangue periférico foram coletadas do plexo periorbital com tubo microcapilar três horas após a administração de MNU.

Este estudo foi aprovado pela Comissão de Ética da Instituição (Protocolo n 021/06).

\section{Processamento e coloração dos cometas}

$\mathrm{O}$ teste do cometa foi desenvolvido segundo protocolo de Singh et al. ${ }^{(25)}$ com modificações ${ }^{(11,14,20)}$, sob baixa luminosidade devido à foto sensibilidade dos reagentes.

Em resumo, lâminas histológicas foram mergulhadas em gel de agarose mantido em banho-maria a $60^{\circ} \mathrm{C} \mathrm{e}$, após remoção do excesso com papel-toalha, secas em temperatura ambiente e mantidas em posição horizontal. Amostras de sangue periférico $(5 \mu \mathrm{l})$ dos animais testados foram misturadas com agarose de baixo ponto de fusão $0,5 \%(100 \mu \mathrm{l})$ e solução tampão fosfato-salino (PBS) livre de $\mathrm{Ca}^{++}$e $\mathrm{Mg}^{++}$. Uma alíquota de cada tubo foi aspirada e gotejada sobre as lâminas previamente revestidas de agarose normal, que foram recobertas por lâminulas. Para garantir adesão adequada das células à agarose, as lâminas foram mantidas na geladeira por cinco minutos. A seguir, e dentro da geladeira por $24 \mathrm{~h}$, realizou-se a liberação do DNA pela lise das células com detergentes (n-Lauroil Sarcosinato) e sais (ácido etilenodiaminotetracético [EDTA], $\mathrm{NaCl}$, Tris, Dimetilsulfóxido e Triton X-100). As lâminas descansaram por 20 minutos em solução de EDTA (1 mM) e NaOH (300 mM), na qual foi realizada a eletroforese em condições alcalinas ( $\mathrm{pH}>13)$, com $25 \mathrm{~V}$ e $300 \mathrm{~mA}$ por 20 minutos. A neutralização dos álcalis foi feita com solução de tampão Tris (Invitrogen).

A coloração foi realizada com prata pelo método descrito por Nadin ${ }^{(20)}$ e Fukumasu ${ }^{(11)}$. Para tanto, misturou-se em uma cubeta $32 \mathrm{ml}$ da solução A ( $50 \mathrm{~g} \mathrm{Na}_{2} \mathrm{Co}_{3}$ quantidade suficiente para [q.s.p.] $1.000 \mathrm{ml}$ de água bidestilada) e $68 \mathrm{ml}$ da solução $\mathrm{B}\left(0,2 \mathrm{~g}\right.$ de $\mathrm{NH}_{2} \mathrm{NO}_{3}, 0,2 \mathrm{~g}$ de $\mathrm{AgNO}_{3^{\prime}}$ $1 \mathrm{~g}$ de ácido silicotungstênico, 500 ul de formaldeido, q.s.p. $1.000 \mathrm{ml}$ de água bidestilada) por um minuto. A seguir, as lâminas foram lavadas por cinco minutos em solução finalizadora ( $1 \mathrm{ml}$ de ácido acético q.s.p. $100 \mathrm{ml}$ de água bidestilada) e depois em água bidestilada por um minuto.

Após todo o procedimento, 50 cometas foram selecionados sob microscopia óptica para análise. O tamanho da amostra foi com base na literatura, que habitualmente utiliza essa quantidade de cometas em testes de cometa comparativos ${ }^{(24,27)}$, apesar de alguns autores recomendarem a análise de até 100 nucleoides $^{(2,19)}$. Para evitar a análise repetida de um mesmo cometa, o processo de seleção das imagens compreendeu o rastreamento contínuo das lâminas do topo para a base ${ }^{(18)}$. Foram fotografadas as estruturas bem formadas e isoladas, até a seleção de 10 unidades para cada classe visual, distribuídas conforme o comprimento da cauda em cinco categorias, que correspondem à gravidade de danos no $\mathrm{DNA}^{(24)}$ : $0=$ sem danos $(<5 \%) ; 1$ = baixo nível de danos ( $5 \%$ a $20 \%$ ); 2 = médio nível de danos (20\% a $40 \%$ ); 3 = alto nível de danos (40\% a 95\%); 4 = totalmente danificados ( > 95\%).

\section{Registro fotográfico, classificação visual e medidas dos cometas}

Foram utilizadas uma câmera fotográfica digital Olympus Camedia C-7070 acoplada a um microscópio Olympus BX41 com aumento de 40 vezes e uma iluminação padronizada. Este sistema permitiu converter o sinal analógico (imagem) em informação digital (numérica), representada por tons de cinza que indicam o brilho de cada ponto dentro da imagem, denominado pixe/(21). As fotografias sequenciais foram adquiridas em modo manual, ISO 100, resolução de $1.024 \times 768$ pixels, 24 bits de cor, densidade de 72 dpi, velocidade do obturador de 1/2000, F 4.8 em zoom máximo. As imagens foram armazenadas em arquivos tipo TIFF. O protocolo fotográfico empregado consistiu em uma escala de 6,29 pixels por micrômetro. 
Para validação do método visual, as imagens selecionadas foram impressas em papel A4 e submetidas a três observadores experientes na análise do cometa, os quais as mediram com uma régua transparente milimetrada. Foi ainda realizada a classificação visual de cada imagem seguindo as cinco categorias ${ }^{(26)}$ mencionadas anteriormente.

\section{Pré-processamento das imagens para reanálise visual e métrica}

As imagens dos cometas foram recortadas digitalmente e pré-processadas de modo automático por algoritmo desenvolvido para o software Imagel 1.38x, que destaca as características do cometa (cabeça e cauda). Para a execução do pré-processamento, após a definição do cometa foram aplicados os recursos do software para filtragem pela cor, aumento do contraste, definição de bordas, padronização de intensidades e remoção do fundo, a fim de preparar a imagem para segmentação e análise (Figura 1A). Para sua aplicação, esses processos foram automatizados.

Essas novas imagens (Figura 2B) foram impressas e reanalisadas pelos avaliadores, que reagruparam os cometas segundo suas classes visuais e os mediram, tal como feito anteriormente.

\section{Processamento automatizado}

Após a aplicação do pré-processamento, as imagens foram processadas por dois algoritmos que envolvem a filtragem estatística espacial (filtros de mediana e mínimo) (Figuras 1B e 1C) e as medidas automaticamente. $\mathrm{O}$ algoritmo I utiliza filtragem de mediana no processamento das imagens e destaque da estrutura central com relação ao fundo (Figura 2C). O algoritmo II emprega filtragem estatística de mínimo e de mediana na individualização dos corpos dos cometas com relação ao fundo (Figura 2D). Para a validação do método automatizado ${ }^{(20)}$, o sistema de análise estimou o comprimento total, o comprimento e o momento da cauda e a intensidade de cor dos cometas.

\section{Análise estatística}

As medidas foram testadas quanto à normalidade pelo teste de Lilliefors ${ }^{(1)}$. A tendência central das amostras foi expressa como média ou mediana, e sua dispersão, como desvio-padrão ou desvio interquartílico.

A precisão das medidas e a retenção de informação de cada canal de cor (R, G e B), um dos passos do processamento da imagem, foram estimadas a partir dos coeficientes de variação, que foram comparados entre si pela análise

\begin{tabular}{|c|c|c|}
\hline A & B & C \\
\hline 1 - Carregamento da imagem & 1 - Preparação da imagem & 1 - Preparação da imagem \\
\hline$\downarrow$ & $\downarrow$ & $\downarrow$ \\
\hline 2 - Seleção manual retangular do cometa & 2 - Inversão do padrão da escala de cinza & 2 - Inversão do padrão da escala de cinza \\
\hline$\downarrow$ & $\downarrow$ & $\downarrow$ \\
\hline 3 - Corte da área de interesse & 3 - Corte da área de interesse & 3 - Corte da área de interesse \\
\hline$\downarrow$ & $\downarrow$ & $\downarrow$ \\
\hline 4 - Inversão da imagem & 4 - Amplificação do contraste & 4 - Amplificação do contraste \\
\hline$\downarrow$ & $\downarrow$ & $\downarrow$ \\
\hline 5 - Amplificação do contraste & 5 - Decomposição nos canais RGB & 5 - Decomposição nos canais RGB \\
\hline$\downarrow$ & - emprego no canal $\mathrm{R}$ & - emprego no canal $R$ \\
\hline 6 - Decomposição nos canais RGB - emprego & $\downarrow$ & $\downarrow$ \\
\hline do canal R & 6 - Aplicação de look up table - fire & 6 - Aplicação de look up table - fire \\
\hline$\downarrow$ & $\downarrow$ & $\downarrow$ \\
\hline 7 - Suavização da imagem - smooth & $\begin{array}{l}7 \text { - Aplicação da filtragem estatística } \\
\text { especial - filtro de mediana }\end{array}$ & $\begin{array}{l}7 \text { - Aplicação da filtragem estatística } \\
\text { especial - filtro de mínimo }\end{array}$ \\
\hline$\downarrow$ & $\downarrow$ & $\downarrow$ \\
\hline $\begin{array}{c}8 \text { - Aplicação de look up table - fire } \\
\downarrow\end{array}$ & 8 - Subtração do background & 8 - Aplicação da filtragem estatística \\
\hline 9 - Medida manual dos cometas & & especial - \\
\hline & & 9 - Subtração do background \\
\hline
\end{tabular}

Figura 1 - Passos de (A) pré-processamento; (B) algoritmo l; e (C) algoritmo II 

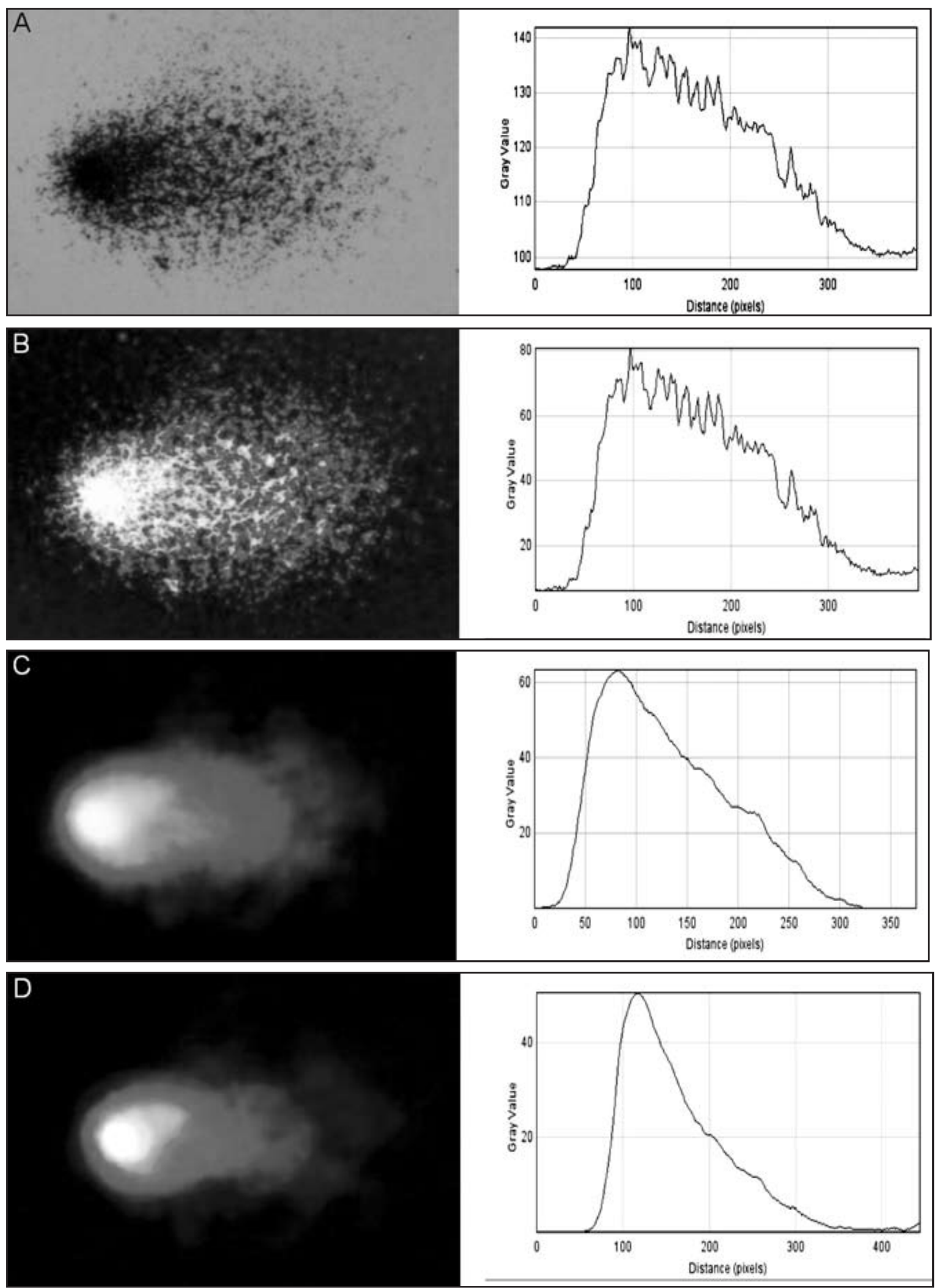

Figura 2 - Fotos do cometa 42 e respectivos histogramas: (A) sem processamento; (B) pré-processamento; (C) algoritmo I; (D) algoritmo II 
de variância (ANOVA). O canal que apresentou o maior coeficiente de variação dos histogramas de cor dos cometas foi o "RED" (R), sendo, portanto, o canal que reteve mais informação digital $(p<0,01)$.

As medidas com distribuição paramétrica foram testadas quanto à correlação de seus valores pelo teste de correlação linear de Pearson; já as medidas não-paramétricas foram analisadas pelo teste de Spearman.

A correlação interpessoal foi estimada pelo coeficiente de correlação intraclasse.

A diferença entre as estimativas dos avaliadores foi analisada pelo teste de Friedman.

Foram adotados como significativos os valores bicaudais de $p<0,05$. Para a análise estatística foi empregado o software Bioestat 5.0(1).

\section{Resultados}

As medidas manuais feitas pelos três avaliadores (Av) foram comparadas e mostraram correlação adequada entre as classificações visuais e as medidas manuais dos cometas nãoprocessados ( $R \geq 0,8$; Tabela 1). Com exceção do parâmetro comprimento da cabeça, na classificação visual as classes das extremidades (classes 0 e 4) tiveram a melhor correlação (dados não mostrados). Apesar dessas boas correlações, as estimativas dos três avaliadores (Av1, Av2, Av3) divergiram entre si em todos os parâmetros avaliados (classes visuais e medidas manuais), não apresentando boa reprodutibilidade geral (Teste de Friedman; Tabela 1). Porém, quando comparadas as estimativas dos Av2 e Av3, foi identificada boa reprodutibilidade com relação à classificação visual, que não diferiram entre si. Já com relação às medidas manuais, somente ocorreu adequada reprodutibilidade quanto as estimativas do comprimento da cauda, feitas pelos Av1 e Av2, e do comprimento da cabeça, feitas pelos Av1 e Av3 (Tabela 1).

Foram também comparadas correlações e reprodutibilidade entre as medidas dos avaliadores realizadas com as imagens pré-processadas (Tabela 2). Em todos os parâmetros avaliados (classes visuais e medidas manuais) houve aumento na correlação entre os avaliadores (Tabela 2), demonstrando valores significativos, como as correlações do comprimento da cauda, sendo a maior entre Av1 e Av3. Também, no geral, houve diminuição na divergência (Teste de Friedman) nas avaliações das amostras pré-processadas (Tabela 2) quando comparadas às avaliações das amostras sem o pré-processamento (Tabela 1). Quando a comparação foi feita dois a dois entre as estimativas dos avaliadores, houve grande reprodutibilidade entre Av1 e Av2 com relação à classificação visual. Com as medidas manuais, a melhor reprodutibilidade ocorreu quanto ao comprimento total do cometa entre Av1 e Av2, comprimento da cabeça entre Av1 e Av3 e comprimento da cauda entre Av2 e Av3 (Tabela 2). Quando comparados os coeficientes de variação das medidas manuais das imagens não-processadas com os das imagens pré-processadas, houve diminuição, indicando aumento da precisão na maioria das medidas ou melhora da reprodutibilidade das análises (Tabela 3).

Nas medidas automatizadas observamos alta correlação $(R>0,8)$ entre as imagens geradas pelo algoritmo I e a média das medidas das imagens pré-processadas feitas pelos três avaliadores, principalmente na comparação do momento da cauda e a percentagem de DNA com classificação visual $(p<0,01)$, e entre os comprimentos totais

\section{Tabela 1 avaliação da reprodutibilidade interpessoal}

\section{Correlação}

$$
\begin{array}{ccc}
\text { Av1 } 1 \text { Av2 Av1 } \times \text { Av3 } & \text { Av2 } \times \text { Av3 } \\
\text { R de Spearman } & R \text { de Spearman } & R \text { de Spearman }
\end{array}
$$

\section{Classificação}

visual

0,80

0,83

0,88

Medidas manuais

Total

Cauda

0,91

0,91
Reprodutibilidade - diferença entre os ranks

Coeficiente

de correlação intraclasse
Teste de

Friedman

Av1 $\times$ Av2 Av1 $\times$ Av3 $\quad$ Av2 $\times$ Av3

$0,14^{*}$

$37,8^{*}$

$52,5^{*}$

$54 *$

1,5

0,85

$70,4^{*}$

$31^{*}$

$52 *$

$83 *$

$A v=$ avaliadores; todos os valores $p<0,01$, exceto * $p<0,05$.

$26,8^{*}$

8,5

$48,5^{*}$ 40 * 
Tabela 2

Análise de imagens pré-processadas de cometas por três avaliadores: estimativas de correlação e

avaliação da reprodutibilidade interpessoal

Correlação

Av1 $\times$ Av2 Av1 $\times$ Av3 Av2 $\times$ Av3

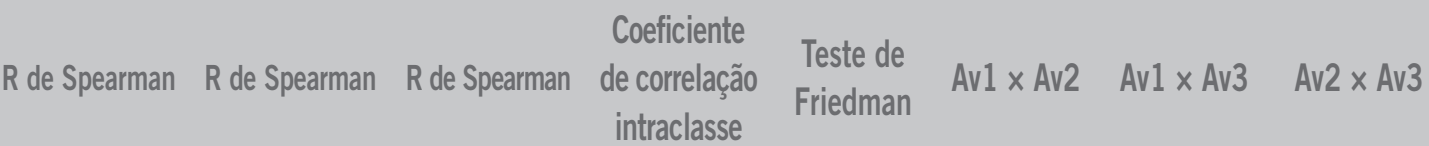

$\begin{array}{lcccccccc}\begin{array}{l}\text { Classificação } \\ \text { visual }\end{array} & 0,96 & 0,69 & 0,71 & 0,65 & 25,27^{*} & 2 & 44,5^{*} & 42,5^{*} \\ \begin{array}{l}\text { Medidas manuais } \\ \text { Total }\end{array} & 0,87 & 0,89 & 0,90 & 0,93 & 42,07^{*} & 10 & 50,5^{*} & 60,5^{*} \\ \text { Cabeça } & 0,53 & 0,58 & 0,82 & 0,47 & 48,67^{*} & 47,5^{*} & 20,5 & 68^{*} \\ \text { Cauda } & 0,88 & 0,93 & 0,92 & 0,54 & 13,71^{*} & 36^{*} & 25,5^{*} & 10,5\end{array}$

Av $=$ avaliadores; $p<0,01$, exceto ${ }^{*} p<0,05$.

\section{Tabela 3 Coeficiente de variação (\%) das medidas dos cometas não-processados e pré-processados}
AV1
AV2
AV3

Não-processados Pré-processados Não-processados Pré-processados Não-processados Pré-processados

Classificação

visual

$0,54-0,47$

0,36

0,46

0,45

0,38

Medidas manuais

\begin{tabular}{|c|c|c|c|c|c|}
\hline Total & 0,34 & 0,31 & 0,33 & 0,30 & 0,38 \\
\hline Cabeça & 0,32 & 0,22 & 0,20 & 0,23 & 0,31 \\
\hline Cauda & 0,54 & 0,49 & 0,50 & 0,53 & 0,62 \\
\hline
\end{tabular}

$(p<0,01)$ e das caudas $(p<0,01)$ (Tabela 4). Também, foi observada alta correlação $(R>0,8)$ entre as medidas das imagens geradas pelo algoritmo II e as médias das medidas manuais das imagens pré-processadas dos três avaliadores, principalmente quando comparamos os comprimentos da cauda, os totais e o momento da cauda e a percentagem de DNA com a classificação visual $(p<0,01)$ (Tabela 5). Em ambos os algoritmos houve baixa correlação do comprimento da cabeça das medidas automatizadas com as medidas manuais pré-processadas. Esse mau desempenho também foi observado nas medidas manuais, quando correlacionadas com as estimativas dos três avaliadores. Houve, porém, melhor correlação com as medidas geradas pelo algoritmo II (Tabelas 4 e 5).

\section{Discussão}

Neste estudo foram comparadas as estimativas de parâmetros de cometas geradas por três avaliadores indepen- dentes a partir de medidas manuais realizadas em imagens não-processadas e pré-processadas. Houve variabilidade das estimativas manuais dos avaliadores, que diminuiu com o pré-processamento digital da imagem. Isso sugere que o pré-processamento digital prévio é um procedimento válido para redução da subjetividade da análise de cometas, aumentando sua precisão e capacidade de detecção de danos mais discretos do DNA.

A análise automatizada das mesmas imagens, após seu processamento com dois algoritmos, indicou melhor desempenho do algoritmo II, que possibilitou melhor análise do histograma gerado. Essas medidas automatizadas demonstraram alta correlação $(R \geq 0,8)$ com os parâmetros obtidos manualmente após o pré-processamento das imagens, o que está de acordo com resultados de outros autores $^{(6)}$. As medidas automatizadas permitiram reduzir a subjetividade da análise, de modo que seu emprego pode ser indicado para ensaios que utilizam nitrato de prata para corar os cometas. 
Tabela 4

Coeficiente de correlação ( $R$ de Spearman) entre as medidas automatizadas (algoritmo I) e a média das medidas dos três avaliadores

\begin{tabular}{|c|c|c|c|c|c|}
\hline \multirow[b]{2}{*}{$\begin{array}{l}\text { Medidas } \\
\text { automatizadas }\end{array}$} & \multicolumn{5}{|c|}{ Medidas Manuais } \\
\hline & Cabeça & Cauda & Total & Classificação & Cauda/total \\
\hline Cabeça & $0,26^{*}$ & & & & \\
\hline Cauda & & 0,82 & & & \\
\hline Total & & & 0,86 & & \\
\hline Cauda/total & & & & 0,73 & 0,69 \\
\hline MT $1^{\mathrm{a}}$ & & & & 0,81 & 0,77 \\
\hline MT $2^{b}$ & & & & 0,43 & 0,44 \\
\hline MT $3^{c}$ & & & & 0,87 & 0,82 \\
\hline MT $4^{d}$ & & & & 0,87 & 0,83 \\
\hline$\% \mathrm{DNA}^{\mathrm{e}}$ & & & & 0,81 & 0,77 \\
\hline
\end{tabular}

Todos os valores $p<0,01$, exceto * $p=0,07$.

${ }^{a}$ MT $1=\%$ DNA cauda $\times$ comprimento da cauda; ${ }^{\mathrm{D} M T} 2=\%$ DNA cauda $\times$ ponto médio do comprimento da cauda; ${ }^{\mathrm{C}} \mathrm{MT} 3=\%$ DNA cauda $\times$ distância dos centros de massa da cauda e da cabeça (cauda medida a partir do meio da cabeça); dMT $4=\%$ DNA cauda $\times$ distância dos centros de massa da cauda e da cabeça (cauda medida a partir do fim da cabeça); e\% de DNA = intensidade cauda/intensidadetotal.

Tabela 5

\begin{tabular}{|c|c|c|c|c|c|}
\hline \multirow[b]{2}{*}{$\begin{array}{l}\text { Medidas } \\
\text { Automatizadas }\end{array}$} & \multicolumn{5}{|c|}{ Medidas manuais } \\
\hline & Cabeça & Cauda & Total & Classificação & Cauda/total \\
\hline Cabeça & 0,55 & & & & \\
\hline Cauda & & 0,89 & & & \\
\hline Total & & & 0,94 & & \\
\hline Cauda/total & & & & 0,85 & 0,81 \\
\hline MT $1^{\text {a }}$ & & & & 0,91 & 0,87 \\
\hline MT $2^{b}$ & & & & 0,69 & 0,63 \\
\hline MT $3^{c}$ & & & & 0,72 & 0,60 \\
\hline MT $4^{d}$ & & & & 0,67 & 0,67 \\
\hline$\%$ de DNAe & & & & 0,86 & 0,80 \\
\hline
\end{tabular}

Todos os valores resultaram em $p<0,01$

aMT 1 = \% DNA cauda $\times$ comprimento da cauda; ${ }^{\mathrm{b} M T} 2$ = \% DNA cauda $\times$ ponto médio do comprimento da cauda; ${ }^{\mathrm{c}} \mathrm{MT} 3$ = \% DNA cauda $\times$ distância dos centros de massa da cauda e da cabeça (cauda medida a partir do meio da cabeça); dMT $4=\%$ DNA cauda $\times$ distância dos centros de massa da cauda e da cabeça (cauda medida a partir do fim da cabeça); $\%$ de DNA = intensidade cauda/intensidadetotal.

O baixo custo operacional, a relativa segurança dos reagentes, a possibilidade de armazenamento das lâminas e a equivalência dos resultados do teste do cometa comparados à técnica clássica com fluorescência são vantagens que fortalecem o emprego da coloração pela prata na execução do teste do cometa ${ }^{(12,20)}$. Uma limitação da coloração pela prata é a grande quantidade de resíduos escuros depositados sobre a lâmina, criando uma "sujeira" que dificulta o processo de filtragem e segmentação digital das estruturas e a avaliação convencional pelos softwares de análise de imagem ${ }^{(12)}$. Para superar essa dificuldade foram desenvolvidos algoritmos para filtrar as partículas não agrupadas aos cometas, que se mostraram eficazes para isolamento e segmentação das imagens dos cometas com relação ao fundo da lâmina.

Além dos depósitos de pigmentos de prata, foi grande o número de células agrupadas ou com alterações na formação 
dos cometas que poderia ser minimizado com maior seleção dos cometas. Considerando que o maior grau de "seleção" dos cometas implicaria em interferências na aleatoriedade da amostragem, principalmente quando o pesquisador conhece as substâncias testadas em cada lâmina.

Outro elemento interferente é a presença de células na metáfase entre a amostra da lâmina, que, com material genético duplicado, formam caudas longas e densas, alterando alguns parâmetros de leitura do teste. A supressão das medidas outliers do sistema previne a influência dessas estruturas na análise.

A coloração concomitante de todo o material do ensaio com a mesma solução do corante, o uso simultâneo de controles positivo e negativo e doses diferentes da substância-teste, o "cegamento" dos pesquisadores que capturam as imagens, assim como um pré-teste com análise visual, são formas de confrontar a qualidade do experimento que será analisado pelo método objetivo automatizado.

Por esse motivo o tratamento do material biológico, a preparação dos espécimes ${ }^{(17)}$, a técnica de coloração, 0 rigor do protocolo da microeletroforese ${ }^{(3)}$, a padronização da captura fotográfica e principalmente a metodologia de seleção dos cometas são elementos que interferem no resultado quantitativo das análises.

O método de análise do teste do cometa corado pela prata ainda não foi padronizado, mas já foi indicado que os resultados das análises das duas colorações são equivalentes ${ }^{(20)}$, sendo portanto a coloração de prata uma alternativa para o teste do cometa, havendo a necessidade de validação do método de análise automatizado.

Os sistemas automatizados geram grande número de parâmetros, sendo os mais empregados na pesquisa científica as estimativas do comprimento da cauda, do momento dela e a porcentagem de DNA nela ${ }^{(16)}$.

O comprimento da cauda tem a desvantagem de não apresentar linearidade com as doses das substâncias-teste, atingindo um platô mesmo que os danos no DNA continuem aumentando.

O momento da cauda também não apresenta linearidade de dose-resposta e não possui uma fórmula de cálculo padronizada, que seja universalmente aceita ${ }^{(7,9)}$. Neste estudo foram utilizados quatro modos de cálculo deste parâmetro, que apresentaram resultados variados, com variações ainda nos dois algoritmos. A fórmula mais utilizada nos ensaios do cometa ${ }^{(16)}$, do Olive tail moment (MT 4), somente apresentou bom desempenho quando foi utilizado o algoritmo I.
A estimativa da percentagem de DNA na cauda é um parâmetro que varia de forma linear com a frequência de quebras do DNA e também é útil para a comparação de resultados internos ou entre diferentes laboratórios ${ }^{(7,9)}$. Sua alta correlação quando comparado às medidas manuais torna a escolha desse parâmetro mais confiável, ainda que, quando comparados, outros parâmetros apresentassem valores de correlação ainda mais altos.

Dessa forma, a alta sensibilidade diagnóstica do teste do cometa deve ser avaliada cuidadosamente, ponderada segundo o comportamento de várias variáveis, que devem ter comportamento gradual de acordo com a concentração da substância testada e correlação direta com as medidas visuais.

O processo mais amplo de validação da análise objetiva de imagem digital do teste do cometa corado pela prata envolvendo um número maior de observadores, concentrações de produtos genotóxicos, inclusive de diferentes categorias, está em andamento.

Novos estudos contemplando outras técnicas de análise de imagem e de automatização do processo, a metodologia de coloração pela prata e fluorescência dos mesmos espécimes, analisadas pelos diferentes softwares, devem corroborar para o uso algoritmos em larga escala na pesquisa de genotoxicidade usando o teste do cometa.

\section{Conclusão}

Foi desenvolvido e validado um sistema de análise automatizado de imagem digital para avaliação quantitativa do teste do cometa corado pela prata.

Foi observada alta correlação entre as medidas estimadas pelo sistema automatizado e as manuais préprocessadas, com as vantagens de o primeiro reduzir a subjetividade da análise feita pelos avaliadores e aumentar a precisão das amostras. Esses resultados indicam a utilidade da análise digital automatizada em pesquisas que utilizem o teste do cometa corado pela prata, o que é reforçado ainda pela gratuidade do software utilizado e pelo uso de microscópio óptico convencional.

Para a completa validação do sistema de análise de imagem digital aqui apresentado será de grande valia a comparação desse sistema automatizado com outros sistemas disponíveis, como os utilizados quando a coloração dos cometas é realizada por métodos de fluorescência. 


\section{Agradecimento}

Os biomédicos Renato Paschoal Prado, Mariana G. Braz e Marize de Lourdes M. Solano gentilmente avaliaram as imagens impressas dos cometas. A biomédica Paula Regina P. Silva disponibilizou o material de sua pesquisa com o teste do cometa para a realização das análises.

\section{Referências}

1. AYRES, M. et al. Bioestat: 3.0 aplicações estatísticas nas áreas das ciências biológicas e médicas. Belém: Sociedade Civil Mamirauá MCT - CNPq Conservation International, 2003.

2. AZQUETA A.; SHAPOSHNIKOV S.; COLLINS A. DNA oxidation: Investigating its key role in environmental mutagenesis with the comet assay. Mutat Res, v. 674, p. 101-8, 2009.

3. BOECK, M. et al. Validation and implementation of an internal standard in comet assay analysis. Mutat Res, v. 469, p. 181-97, 2000.

4. BÖCKER, W. et al. Automated Comet Assay Analysis. Cytometry, v. 35, p. 134-44, 1999

5. BÖCKER, W. et al. Image analysis of comet assay measurements. Int. J. Radiat. Biol, v. 72, n. 4, p. 449-60, 1997.

6. COLLINS, A. et al. Comet assay in human biomonitoring studies: reliability, validation, and applications. Environ Mol Mutagen, v. 30, p. 139-46, 1997.

7. COLLINS, A. R. et al. The comet assay: topical issues. Mutagenesis, v. 23, n. 3, p. 143-51, 2008.

8. COLLINS, T. J. ImageJ for microscopy. Biotechniques, v. 43, n.1, p. 25-30, 2007.

9. DEHON, G. et al. Validation of an automatic comet assay analysis system integrating the curve fitting of combined comet intensity profiles. Mutat Res, v. 650, n. 2, p. 87-95, 2008.

10. FAIRBAIRN, D. W. et al. The comet assay: a comprehensive review. Mutat Res, v. 339, p. 37-59, 1995.

11. FUKUMASU, $\mathrm{H}$. et al. Protective effects of guaraná (Paullinia cupana Mart.var. Sorbilis) against DENinduced DNA damage on mouse liver. Food Chem Toxicol, v. 44, p. 862-7, 2006.

12. GARCIA, O. et al. Measurements of DNA damage on silver stained comets using free Internet software. Mutat Res, v. 627 , p. 186-90, 2007

13. HARTMANN, A. et al. Recommendations for conducting the in vivo alkaline Comet assay. Mutagenesis, v. 18, n. 1, p. 45-51, 2003.

14. HARTMANN, A. et al. Genotoxic effects of chemicals in the single cell gel (SCG) test with human blood cells in relation to the induction of sister choromatid exchanges (SCE). Mutat. Res, v. 346, p. 49-56, 1995.
15. KENT, C. R. H. et al. The comet moment as a measure of DNA damage in the comet assay. Int. J. Radiat. Biol, v. 67, n. 6, p. 655-60, 1995.

16. KUMARAVEL, T. S. et al. Reliable comet assay measurements for detecting DNA damage induced by ionising radiation and chemicals. Mutat Res, v. 605, p. 7-16, 2006.

17. LOVELL, D. P. et al. Statistical issues in the use of the comet assay. Mutagenesis, v. 23, n. 3, p. 171-82, 2008.

18. MCCARTHY, P. J. et al. Evaluation of manual and analysis quantification of DNA damage in the alkaline comet assay. Mutagenesis, v. 12, n. 4, p. 209-14, 1997.

19. MEDINA, L. F. C. et al. Genotoxicity of aminohydroxynaphthoquinones in bacteria, yeast, and Chinese hamster lung fibroblast cells. Mutation Research, v. 650, p. 140-9, 2008.

20. NADIN, S. B. et al. A silver staining method for single-cell gel assay. J Histochem Cytochem, v. 9, p. 1183-6, 2001.

21. OBERHOLZER, M. et al. Methods in quantitative image analysis. Histochem. Cell Biol, v. 105, p. 333-55, 1996.

22. OLIVE, P. L. Cell proliferation as a requirement for development of the contact effect in Chinese hamster V79 spheroids. Radiat Res, v. 117, p. 79-92, 1989.

23. OSTLING, O. et al. Microelectrophoretic study of radiationinduced DNA damages in individual mammalian cells. Biochem Biophys Res Commun, v. 123, p. 291-8, 1984.

24. RIBEIRO, D. A. et al. Fluoride does not induce DNA breakage in Chinese hamster ovary cells in vitro. Braz Oral Res, v. 3, p. 192-6, 2004.

25. SINGH, N.P. et al. A simple technique for quantitation of low levels of DNA damage in individual cells. Exp. Cell. Res, v. 175, p. 184-91, 1988.

26. SPEIT, G. Protocol for the application of the alkaline single cell gel test (SCG-Test or Comet assay) to detection of DNA damage in eukaryote cells. Publicação avulsa, 1995.

27. WIKLUND, S. J. et al. Aspects of design and statistical analysis in the Comet assay. Mutagenesis, v. 18, n. 2, p. 167-75, 2003.

Endereço para correspondência

Hélio Amante Miot

Departamento de Dermatologia e Radioterapia da FMB/UNESP

Campus Universitário de Rubião Júnior

CEP. 18618-000 - Botucatu-SP

Tel.: (14) 3882-4922

Fax: (14) 3882-4922

e-mail: heliomiot@fmb.unesp.br 